\title{
Trans-radial Angioplasty of Anomalous Origin of Right Coronary Artery from Left Sinus of Valsalva - A Single-centre Experience
}

\author{
Sahela Nasrin ${ }^{1}$, F. Aaysha Cader ${ }^{2}$, Shitil Ibna Islam³ ${ }^{3}$ Humayan Kabir ${ }^{4}$, \\ Masuma Jannat Shafi ${ }^{5}$, M. Maksumul Haq ${ }^{6}$
}

\begin{abstract}
:
Background: Percutaneous coronary intervention (PCI) to anomalous coronary arteries remain a challenge in current practice, but can be overcome with appropriate techniques and devices. The objective of this study is to explore the challenges and techniques for success in $\mathrm{PCl}$ of anomalous origin of right coronary artery from left sinus of Valsalva (RCA-LSV) through the trans-radial route.

Methods: This study consisted of 13 patients who underwent $\mathrm{PCl}$ for an angiographically significant stenosis in RCA-LSV between November 2017 to March 2020. The procedural details including numbers of catheters used, access, hardware, techniques, duration of procedure, volume of contrast and complications were recorded and statistically analysed.
\end{abstract}

Results: The most frequent site for RCA-LSV is at the level of left main stem (LMS) $(53.8 \%)$, with $30.8 \%$ being just above the LMS level and $5.4 \%$ being just below the LMS level. Male to female ratio was 5.5:1. Mean age was $53.7 \pm 6.7$ (range;42-64) years. $76.9 \%$ of our patients were diabetic, $92.3 \%$ hypertensive, $84.6 \%$ dyslipidaemic, smoker \& CKD were $23.1 \%$ each. PCI was done successfully in $100 \%$ cases. Our default route was transradial for coronary angiography. Angioplasty was performed through trans-radial route in $92.3 \%$ and transfemoral in $7.7 \%$, with a single case requiring switch over from radial to femoral route. The average number of guide

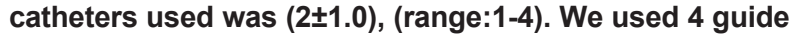

catheters in 2 cases, while the rest of the cases were done by single guide catheter. The guide catheter hooked the coronary ostium selectively and off ostium in $46.2 \%$ cases each, while in $7.6 \%$ cases it was deeply engaged. Anchoring wire to enhance the guide support was used in $7.7 \%$ of cases. The mean duration of the procedure was 33.8 minutes (range: 15-65 minutes), the mean volume of contrast used was 61.5 (range:30-150) $\mathrm{ml}$. We used single stent in $61 \%$ cases and two stents in $39 \%$ cases. Average stent diameter was 2.9 (range;2.5-3.50) $\mathrm{mm}$, length was 28.6 (range;12-43) $\mathrm{mm}$. From among a range of guides used for angioplasty, Judkin's left (JL) and Judkin's Right (JR) successfully cannulated the RCALSV in $76.9 \%$ \& $23.1 \%$ respectively. We used Ikari Left (IL) guide catheter in RCA-LSV associated with subclavian tortuosity to enhance guide support. Majority of the lesions stented were of ACC/AHA classification of Type A \& B lesions ( $38.5 \%$ each), followed by Type C $(23 \%)$ lesion.

Conclusion: To the best of our knowledge, this is the first report of transradial PCI to RCA-LSV in Bangladesh, describing our experiences and techniques, with locally available hardware. PCI of RCA-LSV through radial route is technically challenging but feasible with reasonable amount of contrast and radiation. Proper localization of ostium and selection of suitable guide catheter like JL or IL is the key to success.

Keywords: anomalous RCA from left sinus of Valsalva (RCALSV), Percutaneous coronary intervention (PCl), transradial

(Bangladesh Heart Journal 2020; 35(1): 28-38)

1. Associate Professor \& Consultant, Ibrahim Cardiac Hospital \& Research Institute, Dhaka, Bangladesh.

2. Assistant Professor \& Associate Consultant, Ibrahim Cardiac Hospital \& Research Institute, Dhaka, Bangladesh.

3. Research Officer, Ibrahim Cardiac Hospital \& Research Institute, Dhaka, Bangladesh.

4. Cath lab Radiographer, Ibrahim Cardiac Hospital \& Research Institute, Dhaka, Bangladesh.

5. Assistant Professor \& Associate Consultant, Ibrahim Cardiac Hospital \& Research Institute, Dhaka, Bangladesh.

6. Professor \& Head of Department, Ibrahim Cardiac Hospital \& Research Institute, Dhaka, Bangladesh.

Address of Correspondence: Dr Sahela Nasrin, Associate Professor \& Consultant, Ibrahim Cardiac Hospital \& Research Institute, Dhaka, Banglades Tel: +8801766089094. E-mail address: nasrin_jhumur@hotmail.com 


\section{Introduction:}

Successful percutaneous coronary intervention $(\mathrm{PCl})$ of congenitally anomalous coronary arteries is technically challenging. There is general belief that femoral approach is associated with better chances of coronary artery engagement and better guide support during PCl of anomalous coronary arteries. This assumption is based on the challenges that we have to face during transradial intervention (TRI). It is the angle between the subclavian and brachiocephalic artery that prevents the guide catheter from sitting snugly on the opposite wall of the aorta. ${ }^{1}$.

Coronary arteries arising from an anomalous origin are uncommon and encountered in only $0.2-1.2 \%$ of patients undergoing diagnostic coronary angiography. ${ }^{2}$ Anomalous origin of right coronary artery (AORCA) is a rare congenital anomaly that was first described in 1948 by White \& Edwards. ${ }^{3}$ The angiographic incidence of AORCA is $0.09 \%$ to $0.25 \% .4,5$ The prevalence of this anomaly is significantly higher in non-white populations. A study by Kaku and colleagues including 17,731 patients undergoing coronary angiography from 1968-1994 in Japan indicated a prevalence of $0.25 \% .{ }^{6}$ An anomalous origin of right coronary artery from left sinus of Valsalva (RCA-LSV) has been reported in $6-27 \%$ of patients with coronary anomalies. ${ }^{7}$ The common location of RCA-LSV is either at the level of left main stem (LMS) or above the ostium of LMS. ${ }^{8}$

Performing percutaneous coronary intervention $(\mathrm{PCl})$ to an anomalous RCA can sometimes be a challenging procedure for interventional cardiologists. This often involves adopting newer techniques, changing of multiple guide catheters or using other tools in the armamentarium of intervention, such as guide extension catheters for proper support of the guide catheter. Selective cannulation of anomalous coronary arteries is often difficult due to an unfavourable angle of the origin of the RCA-LSV. In such a case PCl can be done by off ostium catheter engagement rather than a selective cannulation. Cannulation of a RCA-LSV depends on several factors, like the size of the aortic root, the exact location of the origin, finally the orientation \& course of the proximal segment of RCA. ${ }^{9}$ Learning curve may be long as it is an incidental and rare finding, especially when it is done through radial route due to poor back-up support. $\mathrm{PCl}$ may be frequently needed in anomalous RCA that arise from the Left Sinus of Valsalva (LSOV), which is known to be associated with an increased predisposition to developing significant epicardial atherosclerotic disease. ${ }^{10}$ Our study supports the feasibility of radial access as an effective route for $\mathrm{PCl}$ of an aberrant right coronary artery from the left sinus of Valsalva (RCA-LSV) .

\section{Materials \& Methods:}

This prospective study presents the challenges encountered in intervening RCA-LSV at a tertiary care center in Bangladesh between November 2017 to March 2020. A total of 13 patients were of RCA-LSV out of 28 patients who were underwent for $\mathrm{PCl}$ of AORCA. We analyzed the angiographic and interventional details of these cases. Our initial view was Left anterior oblique (LAO) cranial 30 degree, as usual. If it was not visualized in that case we reviewed the previous images those were taken for left system for clues. If there was still no yield, we took a sinus shot or aortic root angiogram (hand injection aortogram) in $30-35^{\circ} \mathrm{LAO}$ projection to visualize the RCA. The aortogram was helpful in defining the shape and size of the aorta, showing the position and orientation of the right coronary ostium. This facilitated the selection of appropriate coronary catheters for engagement of the anomalous RCA. As our default route was radial, we took all the shots by $5 \mathrm{~F}$ Tiger (TIG) catheter mostly. Diagnostic angiogram with TIG catheter is generally more comfortable for negotiation of anomalous RCA than Judkin's Right (JR). For RCA-LSV, our initial guide catheter was Judkin's Left (JL). The right coronary artery normally arises from the right anterior facing sinus, its ostium located in the middle of the sinus just above the free leaflet margin of the aortic leaflet and below the sinotubular junction. When selective cannulation failed, catheter changes were done according to preference of the performer.

Data were processed and analyzed using SPSS (Statistical Package for Social Sciences), version 25.0 for Windows (SPSS Inc., Chicago, Illinois, USA). The test statistics used to analyze the data were descriptive statistics like continuous variables will be expressed as mean and standard deviations from the mean (means \pm $\mathrm{SD}$ ) and categorical variables will be expressed as frequency with corresponding percentage.

\section{Result:}

Mean age of the study population was $53.7 \pm 6.7$ (range: 42-64) years. Male to female ratio was 5.5:1. Other demographic and baseline characteristics are detailed in Table I. 
Table-I

Baseline characteristics $(n=13)$

\begin{tabular}{lccc}
\hline Demographic parameters & Frequency & Percentage (\%) & Mean \pm SD (Range) \\
\hline Age (year) & - & - & $53.7 \pm 6.7(42-64)$ \\
Sex & 11 & 84.6 & - \\
Male & 2 & 15.4 & - \\
Female & & & - \\
Risk factors & 10 & 76.9 & - \\
DM & 12 & 92.3 & - \\
HTN & 11 & 84.6 & - \\
DL & 3 & 23.1 & - \\
Smoker & 3 & 23.1 & - \\
CKD & & & - \\
Diagnosis on admission & 4 & 30.8 & \\
STEMI & 3 & 23.1 & - \\
NSTEMI & 6 & 46.2 & - \\
UA & & & - \\
Left Ventricular (LV) ejection fraction & 4 & 30.8 & \\
Normal LV function & 8 & 61.5 & \\
Mild LV systolic dysfunction & 131 & 7.723 .17 .7 & \\
Moderate LV systolic dysfunctionPrior & & & \\
myocardial infarction (MI)Prior PCI & & & \\
\hline
\end{tabular}

The frequent site for RCA-LSV is at the level of LMS (53.8\%), followed by just above the LMS (30.8\%) level. Only $15.4 \%$ RCA-LSV had ostia just below the LMS level.(Figure 1)

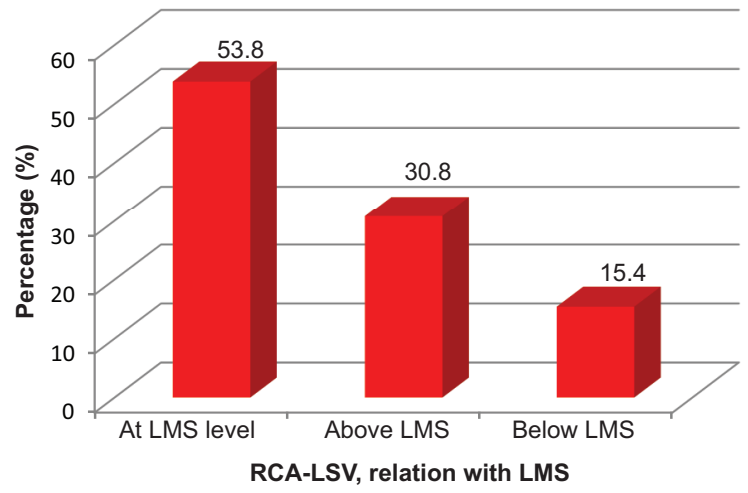

Fig.-1: RCA-LSV, relation with LMS

RCA-LSV was most frequently cannulated successfully by means of Judkins left (JL) guide in $76.9 \%$ of cases, and alternately by Ikari left (IL) guide ( $23.1 \%$ of cases). (Figure 2)

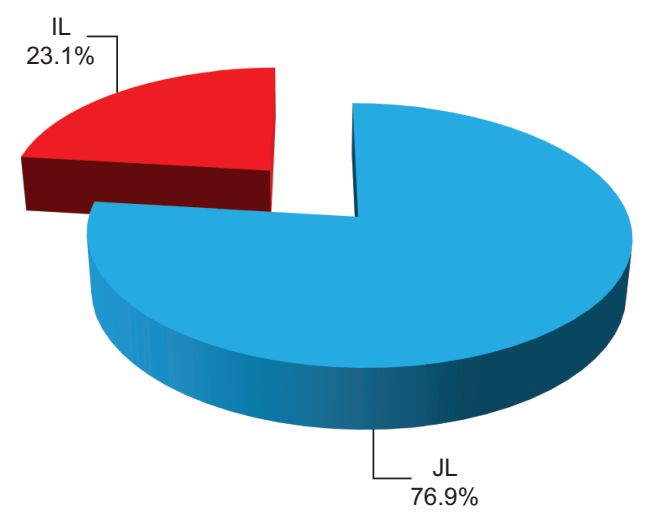

Fig.-2: Successful Guiding catheters used

Regarding the engagement of guide catheter, it hooked the coronary ostium selectively in $46.2 \%$ cases, while it had to be kept off ostium co-axial with the coronary in same percentage of cases and deep intubation with monitoring of the pressure was done in $7.6 \%$ case. (Figure 3) 


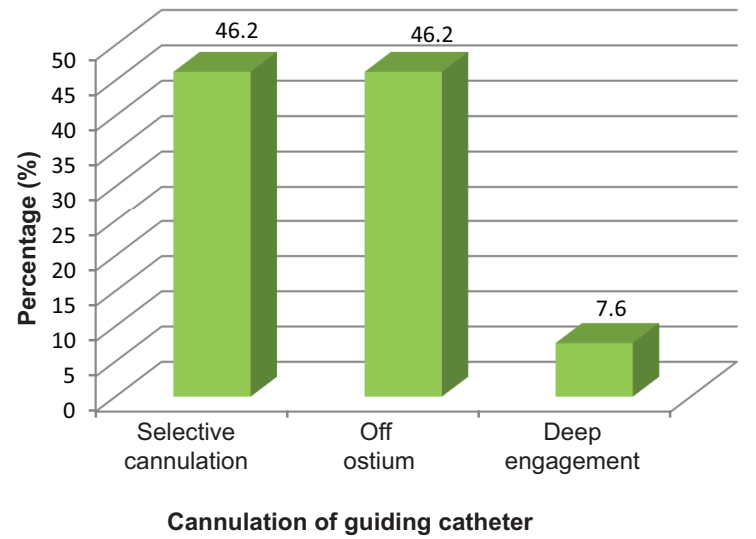

Angioplasty was performed through trans-radial route in 12 patients $(92.3 \%)$ and trans-femoral in 1 patient $(7.7 \%)$. Switch over from radial to femoral access was required in 1 patient $(7.7 \%)$.

The average number of guide catheters used was (2 \pm 1.0$)$, (range; $1-4)$. A single catheter was used in $84.6 \%$ cases. . The mean duration of procedure was 33.8 minutes \& range was (15-65) minutes. Other procedural characteristics including types of lesions stented, stent diameters and lengths, contrast volume and other procedural details such use of anchoring wires for support etc are stated in table II.

Fig.-3: Cannulation of guiding catheter

Table-II

Procedural characteristics $(n=13)$

\begin{tabular}{|c|c|c|c|}
\hline Parameters & Frequency & Percentage & Mean \pm SD(Range) \\
\hline \multicolumn{4}{|c|}{ Type of vessel(ACC/AHA classification) } \\
\hline TypeA & 5 & 38.5 & - \\
\hline Type B & 5 & 38.5 & - \\
\hline Type C & 3 & 23.0 & - \\
\hline \multicolumn{4}{|l|}{ Vascular access } \\
\hline Radial & 12 & 92.3 & - \\
\hline Femoral & 1 & 7.7 & - \\
\hline \multicolumn{4}{|c|}{ Number of guide catheters used } \\
\hline 1 Cath & 11 & 84.6 & - \\
\hline 4 Cath & 2 & 15.4 & - \\
\hline \multicolumn{4}{|l|}{ Number of stents used } \\
\hline Single stent & 8 & 61.5 & - \\
\hline Double stent & 5 & 38.5 & - \\
\hline \multicolumn{4}{|l|}{ Segment } \\
\hline proximal & 1 & 7.7 & - \\
\hline mid & 12 & 92.3 & - \\
\hline distal & 4 & 30.8 & - \\
\hline Average Stent Diameter & - & - & $2.9 \pm 0.3(2.5-3.5)$ \\
\hline Average Stent Length & - & - & $28.6 \pm 9.6(12-43)$ \\
\hline \multicolumn{4}{|l|}{ Stent } \\
\hline single & 8 & 61.5 & - \\
\hline double & 5 & 38.5 & - \\
\hline Predilatation & 9 & 69.2 & - \\
\hline Postdilatation & 8 & 61.5 & - \\
\hline \multicolumn{4}{|l|}{ Creatinine } \\
\hline Normal & 12 & 92.3 & - \\
\hline AKI & 1 & 7.7 & - \\
\hline Average Cath used & & & $1.8 \pm 1.1(1-4)$ \\
\hline Duration Procedure(minute) & - & - & $33.8 \pm 14.3(15-65)$ \\
\hline Dye Amount(ml) & - & - & $61.5 \pm 41.4(30-150)$ \\
\hline \multicolumn{4}{|l|}{ No of Guidewires } \\
\hline 1 & 11 & 84.6 & - \\
\hline 2 & 2 & 15.4 & - \\
\hline Anchoring Wire & 1 & 7.7 & \\
\hline
\end{tabular}



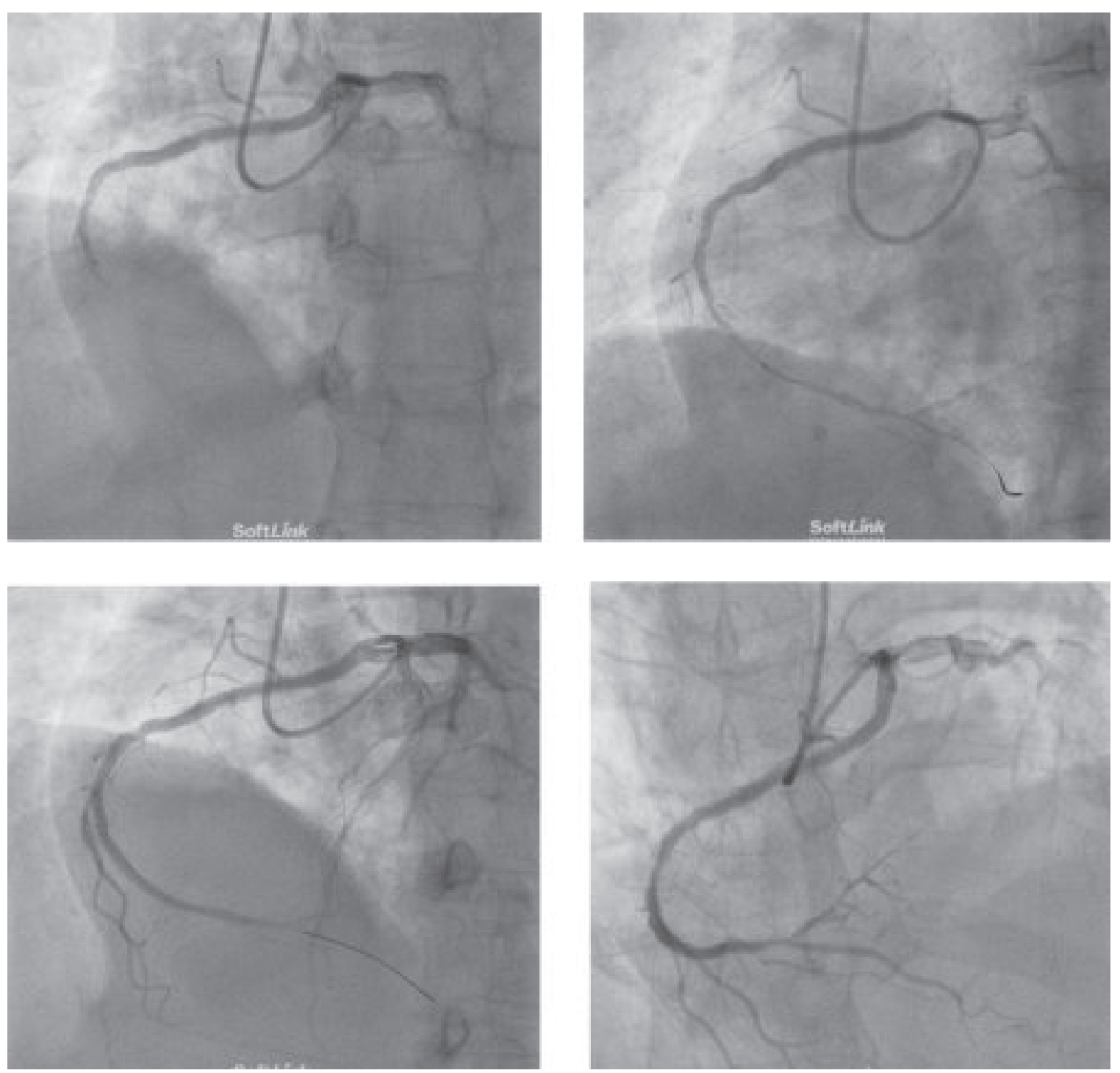

Fig.-4: PCl to totally occluded RCA-LSV. Guide catheter JL $3.55 \mathrm{Fr}$
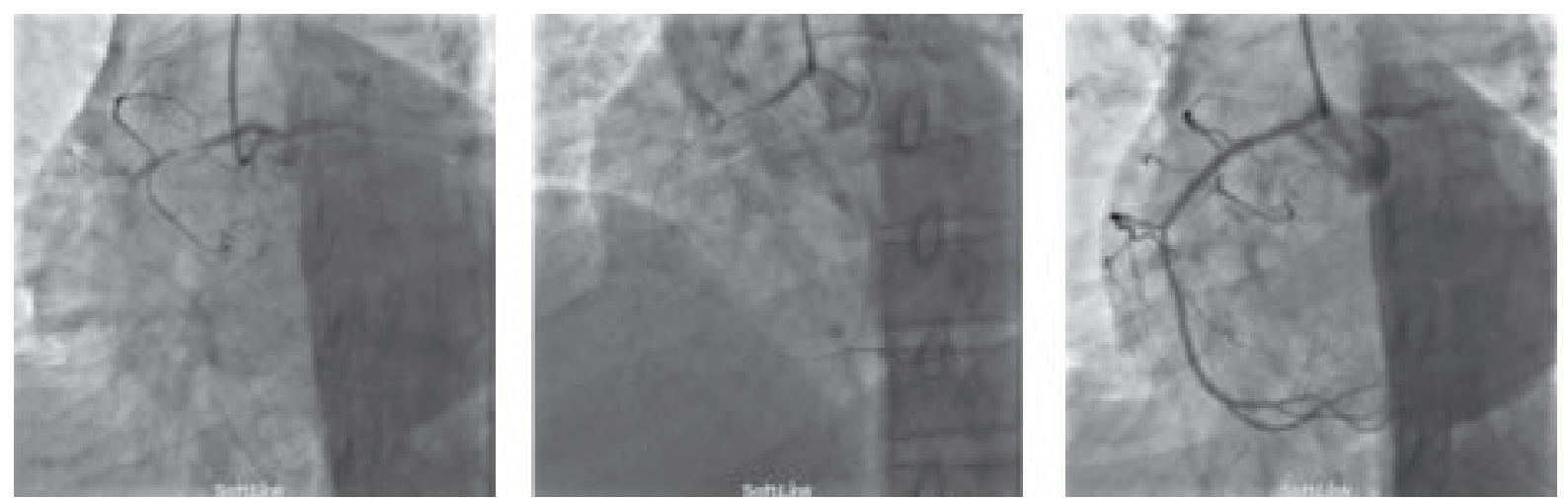

Fig.-5: PCI to totally occluded RCA-LSV, successful guide catheter 5F JL, off ostial engagement 

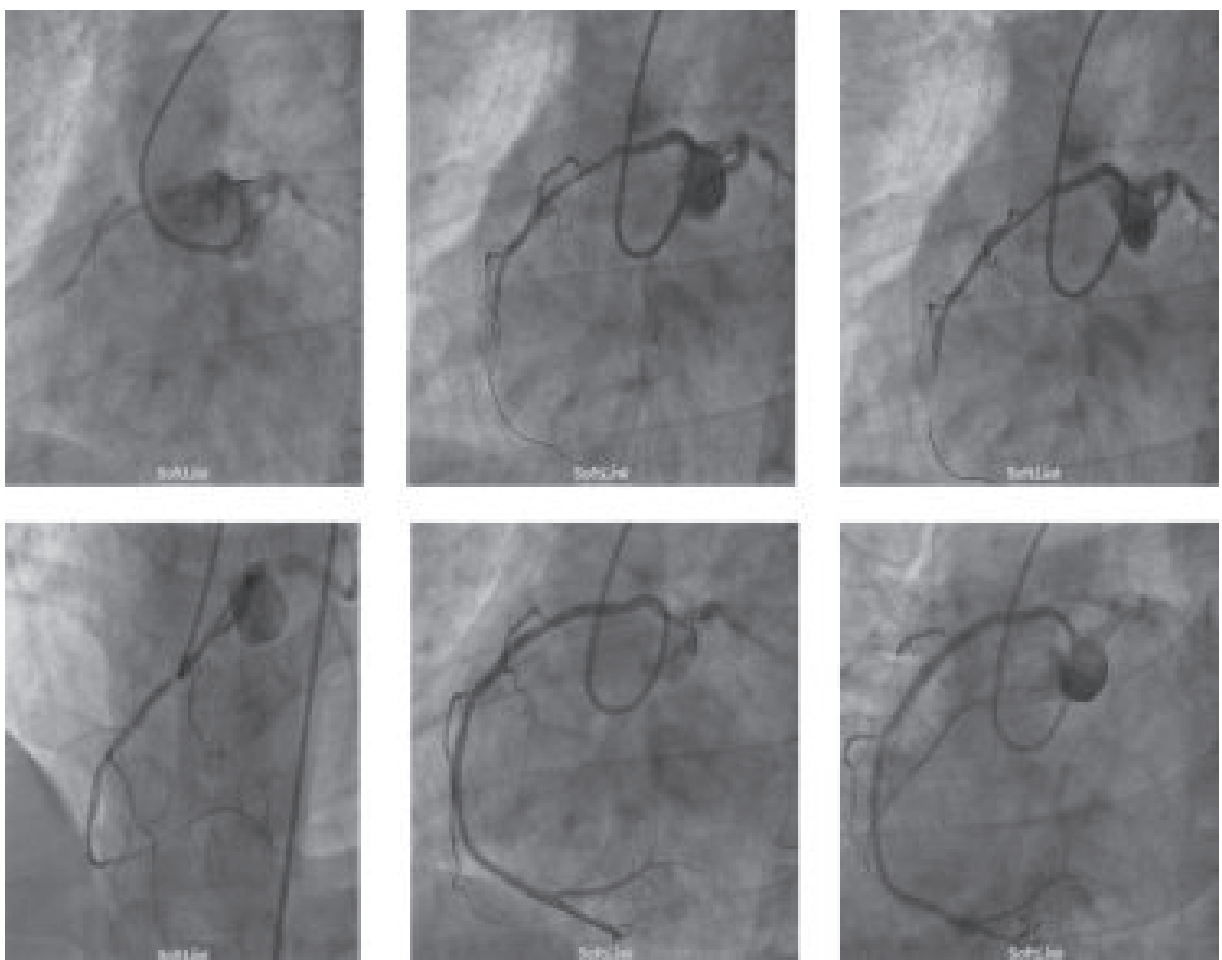

Fig.-6: $P C I$ to totally occluded RCA-LSV, selective engagement by $6 F \mathrm{JL} 3.5$ guide catheter was done, requiring greater support and switch-over to femoral access.
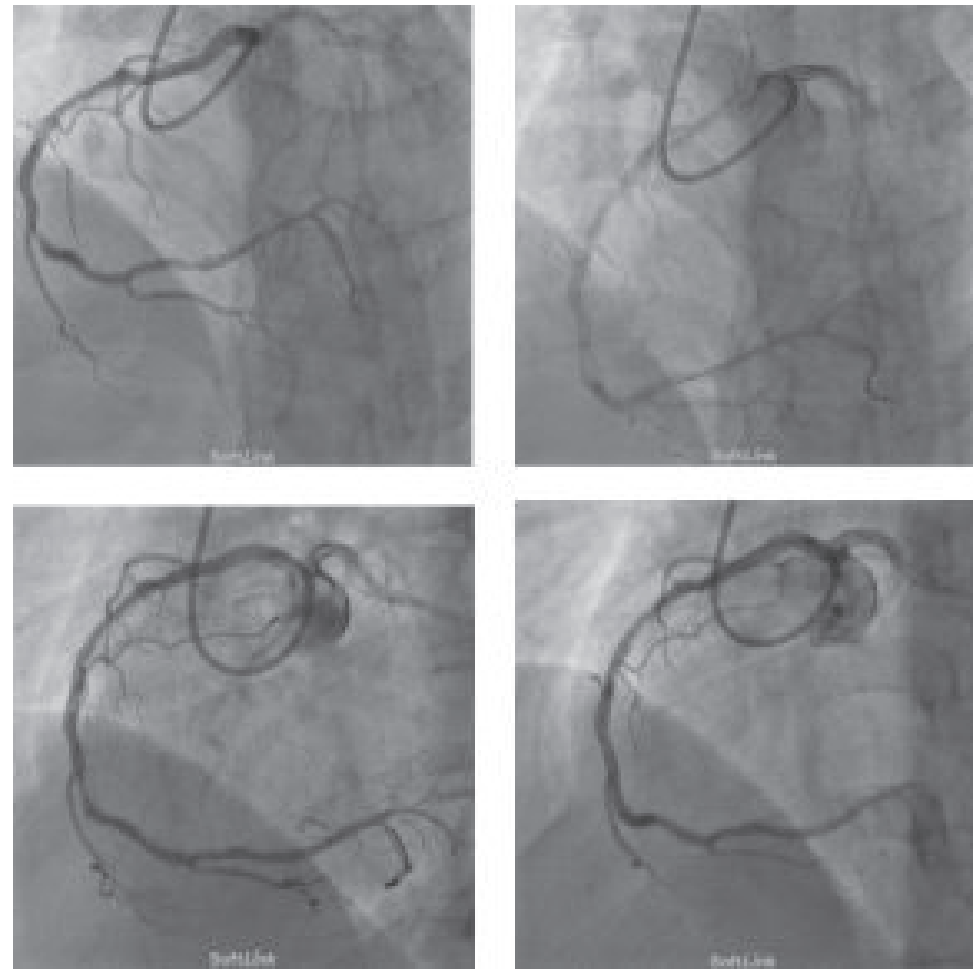

Fig.-7: Stenting of RCA-LSV, Type B lesion, coaxial engagement, 2 stents deployed, one in PLV including distal RCA, another in mid RCA, guidecatheter- JL $3.56 \mathrm{~F}$ 

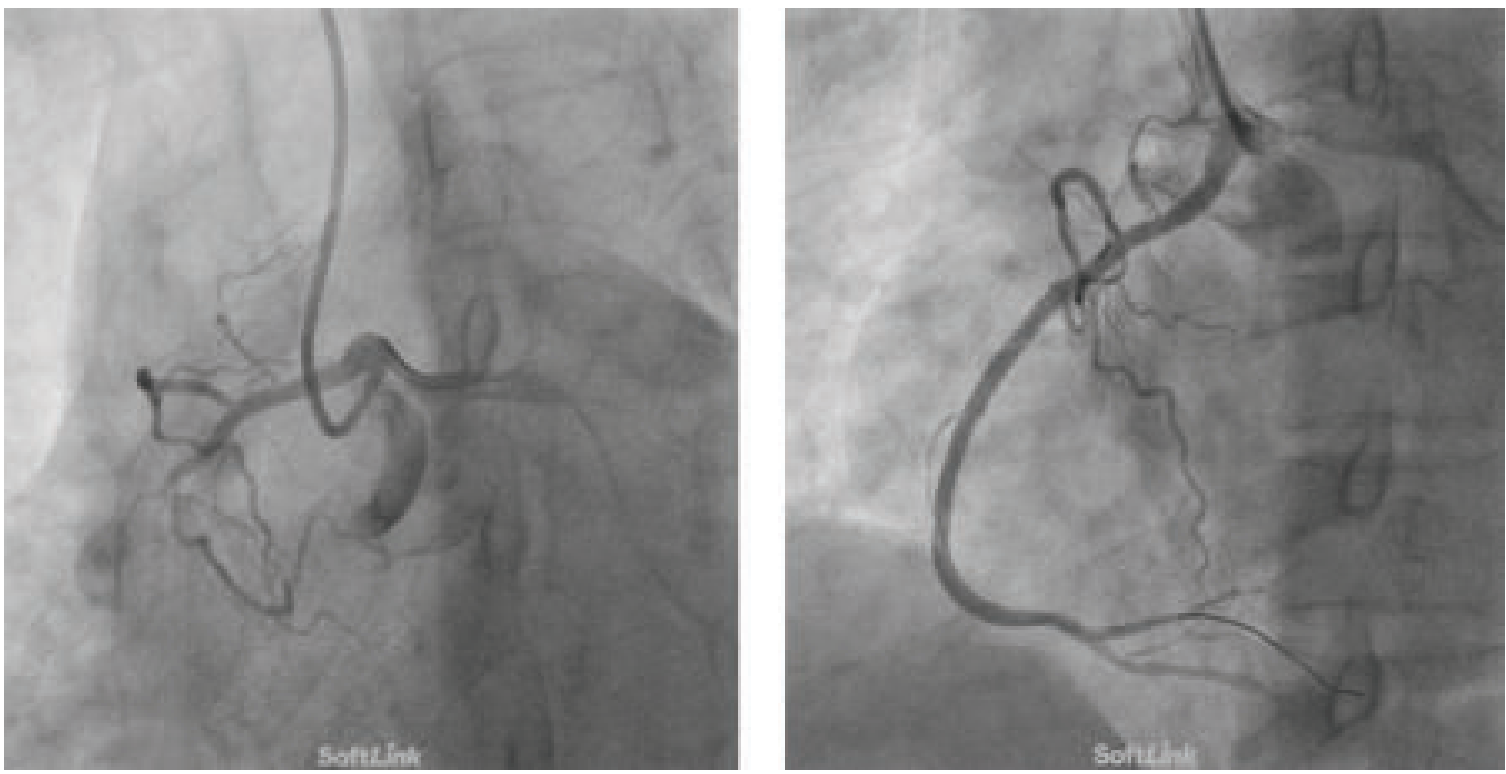

Fig.-8: RCA arises from left coronary sinus \& after successful PPCI with IL guide catheter, off ostium catheter engagement
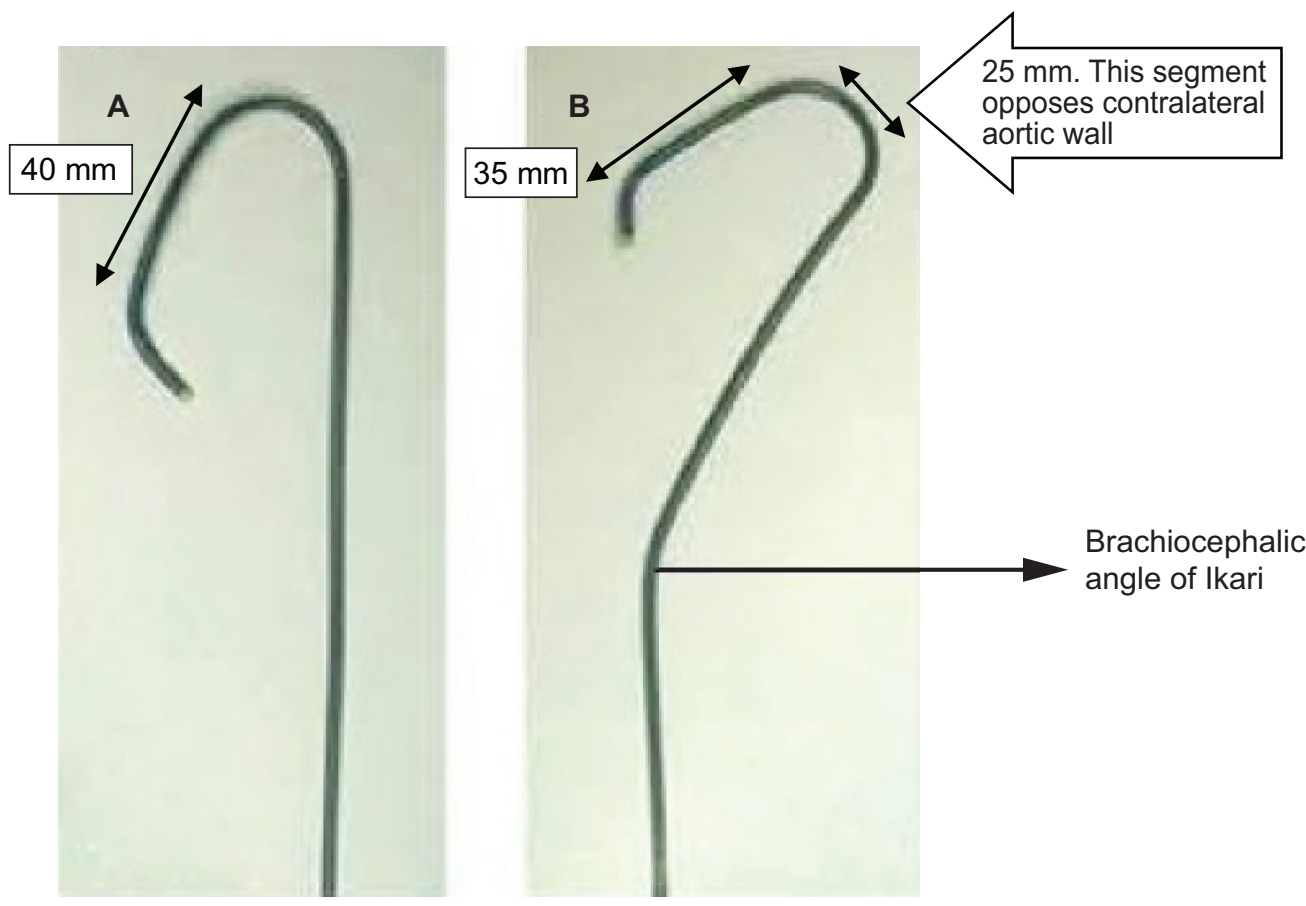

Fig.-9: Panel A-JL, 3.5 guide catheter, panel B-The Ikari Left 3.5 guide catheter

\section{Discussion:}

The exact location of AORCA was well delineated on routine coronary angiographic views, supplemented by modified views, non-selective sinus and aortic root angiogram. A similar procedure was adopted by Jim et al. ${ }^{11}$ Occasionally, an AORCA may be associated with an inter-arterial or intramural course, which can be well documented by 3D-CT angiogram. ${ }^{12,13}$ This was however, not required in our cases.

The commonest site of RCA-LSV was at the level of LMS (53.8\%), followed by superior to LMS (30.8\%). (Figure 4). The commonest site found by Uthayakumaran, et al ${ }^{8}$ 
was above the LMS ( 8 out of 17 patients), followed by midline, i.e. at the level of LMS ( 6 out of 17 patients). They only reported 3 cases below the level of LMS, which is consistent with our study (2/13-15.4\%).

Commonest diseased segment found by Nemani, et al ${ }^{14}$ \& Chun-Chung, et al ${ }^{15}$ was the mid segment of RCA (65\% \& 83.3\% respectively), similar to our results $(92.3 \%)$ (figure:4). The juxta commissural location of the ostia of AORCA and initial tangential course of the anomalous artery in relation to the aortic wall make it difficult to engage the anomalous RCA with routine guiding catheter. ${ }^{16}$ So intervention in AORCA depends on proper selection with skillful manoeuvres of the guide, i.e. technique, with adjunction of some extra support of catheter by anchoring wire or buddy wire.

Some challenges for the operator are the anatomy of AORCA (location and configuration of the ostium, immediate take off angle, lesion location and tortuosity of the vessel) and the diameter of the aortic root. ${ }^{17-19} \mathrm{~A}$ retrospective study of elective cases by Uthayakumaran, et al, ${ }^{8}$ showed that the average number of guide catheters used for a single $\mathrm{PCl}$ of AORCA was three or more, which indicates the challenges involved in the intervention of AORCA. In our study, four guides were consecutively attempted to cannulate the AORCA in a case at the beginning of a study, and in another case with subclavian tortuosity; subsequently the number of guides required gradually diminished with increasing experience in such cases of RCA-LSV. The average number of guides used by Nemani, et al ${ }^{14}$ was two, which is consistent with our study.

Guide selection depends on the immediate take off angle of the RCA rather than the anterior or posterior displacement of the ostium. 5 of 6 French guides were used in our cases owing to the transradial access route. Besides this, due to smaller body build and relatively smaller diameter of the radial artery $(2.2 \pm 0.03 \mathrm{~mm})^{20}$ in our population, we could not use guides larger than 6 French, due to potential radial artery spasm. In their study, Nemani, et al ${ }^{14}$ reported that the guide hooked the coronary selectively in $40 \%$ patients, while it had to be kept off ostium co-axial with the coronary in $55 \%$ patients, deep intubation with monitoring of the pressure in $5 \%$ of cases, all of which were strikingly similar to our approach.

$\mathrm{PCl}$ for RCA-LSV presents additional technical challenges. When the RCA arises below the left sinotubular ridge, it usually has a slit-like ostium and takes an acute rightward course that precludes the coaxial engagement of most of the currently available guiding catheters. Furthermore, it is usually difficult to perform successful $\mathrm{PCl}$ to a totally occluded RCA due to the lack of adequate backup support from the guide. ${ }^{16,}{ }^{21-25} \mathrm{We}$ did 3 totally occluded RCA-LSV, one by IL guide catheter and 2 cases by $\mathrm{JL}$ guide catheter, all of which were approached transradially (Figures 4 and 5).

The ostium of RCA arising from the LSOV is usually located anteriorly next to the ostium of the left main (LM) artery. The ostium of the LM artery can therefore be used as a useful landmark. The operator advances the $\mathrm{JL}$ or IL catheter to the level close to LM ostium and then rotates clockwise or anticlockwise and further advances it. This simple maneuver will engage the anomalous RCA orifice coaxially. The Leya catheter, a modified Amplatz left (AL) guiding catheter with a right-angled tip, was designed specifically for $\mathrm{PCl}$ of a RCA-LSV. ${ }^{25}$ In absence of this guide catheter in our shelf, JL $5 \mathrm{~F}(76.9 \%)$ remained the most successful guide catheter in our cases. This corelates with that of Uthayakumaran et al.. who used JL guides in 10 out of 17 cases. $^{8}$ Two cases of RCA-LSV in the study by Cohen et al., were stented by $6 \mathrm{~F}$ JL guide. ${ }^{22}$ Some cases of Uthayakumaran and Topaz, et al, were done by AL guide. ${ }^{26}$ In the study of Chun-Chung, et al the diameter of the guiding catheter was 6 French in five patients, and 5 French in one patient. ${ }^{15}$ In our study we used $5 \mathrm{~F}$ guide catheter in $69.2 \%$ cases (9 patients).

In the study done by Nemani, et al, ${ }^{14}$ switch over from radial to femoral access was required in 4 patients $(20 \%)$. In our study it was only in 1 patient (Figure 6). Uthayakumaran et al. ${ }^{8}$ who performed 17 cases of $\mathrm{PCl}$ to RCA-LSV used a predominantly femoral route, with a single case being switched over from femoral to radial in one case.

The mean amount of contrast we used was $61.5 \mathrm{ml}$. The mean duration of procedure was 33.8 minutes. The average volume of contrast used by Nemani, et al ${ }^{14}$ was $124 \mathrm{ml}$ (range 60-200 ml) and the mean flouroscopy time was 22 minutes (range of 9-38 mins). The duration of intervention was ranged from 18 to 103 minutes (median 44 minutes) in the study done by Chun-Chung, et al for RCA-LSV. ${ }^{15}$ The mean fluoroscopy time was $20.7 \mathrm{~min}$ (range: $12.2-63.3 \mathrm{~min}$ ) and the mean amount of contrast used was $210 \mathrm{ml}$ (range: $120-320 \mathrm{ml}$ ) in the study done by Uthayakumaran, et al. ${ }^{8}$ We experienced no procedure-related complications, similar to Chun-Chung, et al. ${ }^{15}$

Despite the low incidence of RCA-LSV, any experienced interventional cardiologist who performs many $\mathrm{PCl}$ procedures may well expect to encounter at least one 
case of it. Therefore one should be cognizant of appropriate $\mathrm{PCl}$ techniques and guides to be used in such a case, especially in case of Primary $\mathrm{PCl}(\mathrm{PPCl})$ where the approach is radial. An adequate knowledge of RCA-LSV obviates the need for switching to femoral access thus saving time in case of PPCl. We encountered a similar case, where $\mathrm{PPCl}$ was successfully performed by IL guide catheter transradially. (Figure:8) A Konstantinos ${ }^{9}$ also performed a case of PPCl of RCA-LSV radially.

In addition to anatomic factors, catheter selection for $\mathrm{PCl}$ is also influenced to a certain degree by operator preference, familiarity, and institutional availability. This explains the difference in catheter selection from our experience, to those by Nemani, et al ${ }^{14}$ \& Sarkar, et al ${ }^{16}$. Furthermore, the procedures were done through transfemoral route by Sarkar, et al. ${ }^{16}$

Regarding the arterial access, our 12 cases, one case of A Konstantinos ${ }^{9}$ and 2 cases of Suryanarayana, et al. ${ }^{27}$ indicate that the radial approach is an excellent strategy for PCl of RCA-LSV. It may be considered as an excellent alternative for $\mathrm{PCl}$ of RCA-LSV, ${ }^{28}$ even when a transfemoral attempt has previously failed. $27,8,29$ It seems that the manipulation of the guide catheter is easier and the provided support is more robust with right radial access.

We used Ikari left(IL-23.1\% case) guide catheter for RCALSV, in case of brachiocephalic/ subclavian artery tortuosity by transradial approach. The primary contact site of IL guide for the RCA is brachiocephalic artery. However, it attaches on the opposite wall of the ascending aorta in power position that provides an extraordinary support for RCA-LSV with subclavian or brachiocephalic tortuosity. It can be done by pushing the guide (IL) along the wire or the balloon shaft; thereby changing the guide shape. ${ }^{30}$ By this manipulation we can obtain the power position of IL for the backup support. The IL guide has greater backup force than the Judkins left (JL), based on the mechanics in case of TRI. IL has a wider angle and longer contact on the opposite wall of the aorta, thereby generating greater backup force. ${ }^{30}$

The IL has three modifications from the JL: (1). The length at the final straight position is shorter (length between the third and the fourth angles) $35 \mathrm{~mm}$ in Ikari, which is $40 \mathrm{~mm}$ in $\mathrm{JL}$. This makes the angle between the guide and the opposite wall of the aorta bigger. (2) The second straight position is longer: $25 \mathrm{~mm}$ more than the $\mathrm{JL}$ guide. This makes the contact area with the aorta larger, thereby increases the friction force. (3) a new primary curve that was added to fit the brachiocephalic arterybrachiocephalic angle (Figure 9). This does not correlate with the backup force but it makes guide control easier and stabilizes the guide position. This essentially means that the IL is a modified $\mathrm{JL}$ catheter designed specifically for TRI. Backup force of the IL is greater than the JL in TRI because the angle between the catheter and the reverse side of the aorta is increased. Furthermore, IL in TRI is shown to be more supportive than a JL in TFI. ${ }^{30}$

From the above discussion it can be concluded that the most effective guide catheter for transradial PCI to RCALSV is most likely the $\mathrm{JL}$ guide. We can also use IL guide catheter considering the tortuosity of the subclavian artery and also where we need extra backup support.

There are several small case series regarding the successful PCI of RCA-LSV, most of which are through femoral approach, ${ }^{24,31,22,26}$ including a relatively larger series of 17 patients by Uthayakumaran et $\mathrm{al}^{8}$. With the experience of our 13-patient series, this study provides a simple and effective framework for the busy interventionalist to successfully engage the RCA-LSV with reduced expenditure of contrast agent and radiation exposure, thus increasing the likelihood of technical success transradially.

\section{Limitation:}

This study was a single center study with a relatively small sample size, given the lower incidence of RCALSV.

\section{Conclusion:}

The right radial access can be considered as a reasonable strategy for PCI of RCA-LSV with JL or IL guide catheter. Both these guides offer better manipulation with more robust support, resulting in technical success.

\section{References:}

1. Patel T, Sanjay Shah S, Pancholy S. Choosing catheter shapes for radial $\mathrm{PCl}$. Cardiac Interventions Today; 2012. Available from: http:// citoday.com/2012/06/choosing-catheter-shapesfor-radial-pci

2. Kimbiris D, Iskandrian AS, Segal BL. Anomalous aortic origin of coronary arteries. Circulation. 1978;58:606-615.

3. White NK, Edwards JE. Anomalies of the coronary arteries. Report of four cases. Arch Pathol. 1948;45:766-71. 
4. Sivri N, Aktoz M, Yalta K, Ozcelik F, Altun A. A retrospective study of angiographic ally determined anomalous coronary arteries in 12,844 subjects in Thrace region of Turkey. Hippokratia. 2012;16: 246-249.

5. Ayalp R, Mavi A, Serc, elik A, Batyraliev T, Gümu“ sburun $E$. Frequency in the anomalous origin of the right coronary artery with angiography in a Turkish population. Int J Cardiol. 2002;82:253-257.

6. Kaku B, Shimizu M, Yoshio H, Ino H, Mizuno S, Kanaya $\mathrm{H}$, et al. Clinical features of prognosis of Japanese patients with anomalous origin of the coronary artery. Jpn Circ J. 1996;60:731e741.19.

7. Yamanaka O, Hobbs RE. Coronary artery anomalies in 126,395 patients undergoing coronary angiography. Catheter Cardiovase Diagn. 21(1990):28-40

8. Uthayakumaran K, Subban V, Lakshmanan A, et al. Coronary intervention in anomalous origin of the right coronary artery (ARCA) from the left sinus of valsalva (LSOV): a single center experience. Indian Heart J. 2014;66:430-434.

9. Konstantinos A, Albert A. Transradial primary angioplasty of anomalous right coronary artery from the left sinus of Valsalva. Indian Heart Journal. 2017,69(issue 3):411-413.

10. Jim MH, Siu CW, Ho HH, et al. Anomalous origin of the right coronary artery from the left coronary sinus is associated with early development of coronary artery disease. J Invasive Cardiol. 2004;16:466-468.

11. Jim $\mathrm{MH}$, Siu CW, Ho HH, et al. Anomalous origin of right coronary artery from the left coronary sinus: incidence, characteristics, and a systematic approach for rapid diagnosis. J Interv Cardiol. 2005;18:101-106.

12. Kadakia J, Gupta M, Budoff MJ. Anomalous "High Take-Off" of the right coronary artery evaluated by coronary CT angiography. Catheter Cardiovasc Interv. 2013;82:E765-E768.

13. Kim HK, Choi YJ, Kang KW, et al. A case of acute thrombotic occlusion of anry sinus: focus on the importance of dual- source computed tomography for failed emergency coronary angiography. Can J Cardiol. 2012;28:759.

14. Nemani L, Jyotsna M, Barik R, Venkata K, Krishna S. Tools and techniques for Chang HC. A Novel Technique for Percutaneous Coronary Intervention for Anomalous Right Coronary Artery A. Journal of Indian College of Cardiology. 2015;5:189-197.

15. Lin CC, Yeh KH, Chou HH, Hsu SY, Chang HC. A Novel Technique for Percutaneous Coronary Intervention for Anomalous Right Coronary Artery Arising from the Left Sinus of Valsalva. Acta Cardiol Sin. 2015;31(3):235-240.

16. Sarkar K, Sharma SK, Kini AS. Catheter selection for coronary angiography and intervention in anomalous right coronary arteries. J Interv Cardiol. 2009;22:234-239.

17. Agarwala R, Kapoor A. The mystery of the lost and found right coronary artery. Catheter Cardiovasc Interv. 2010;76:969-972.

18. Fang HY, Wu CC, Wu CJ. Successful transradial antegrade coronary intervention of a rare right coronary artery high anterior downward take off anomalous chronic total occlusion by doubleanchoring technique and retrograde guidance. Int Heart J. 2009;50:531-538.

19. Turgut O, Tandogan I, Dizman R. Use of the RCB guide in $\mathrm{PCl}$ of a chronic total occlusion in an anomalous right coronary artery with high anterior takeoff. J Invasive Cardiol. 2009;21:E70-E72.

20. Chowdhury M, Kabir C, Nasrin S, et al. Radial Artery Patency after Trans-radial Cardiac Catheterization in Bangladeshi Population. University Heart Journal. 2014;10(2):66-72.

21. Azzarelli S, Amico F, Giacoppo M, et al. Primary coronary angioplasty in a patient with anomalous origin of the right coronary artery from the left sinus of Valsalva. J Cardiovasc Med. 2007;8:943-945.

22. Cohen MG, Tolleson TR, Peter RH, et al. Successful percutaneous coronary intervention with stent implantation in anomalous right coronary arteries arising from the left sinus of Valsalva: a report of two cases. Catheter Cardiovasc Interv. 2002;55:105-108.

23. Praharaj TK, Ray G. Percutaneous transluminal coronary angioplasty with stenting of anomalous right coronary artery originating from left sinus of Valsalva using the Voda guiding catheter: a report of two cases. Indian Heart J. 2001;53:79-82.

24. Chakraborty B, Chan CN, Tan A. Percutaneous transluminal coronary angioplasty of an anomalous right coronary artery arising from a separate ostium in the left sinus of Valsalva: A case report. Angiology. 1995;46:629-632. 
25. Qayyum U, Leya F, Steen L, et al. New catheter design for cannulation of the anomalous right coronary artery arising from the left sinus of Valsalva. Catheter Cardiovasc Interv. 2003;60: 382-388.

26. Topaz O, Cowley MJ, Alpman A et al. Percutaneous transluminal coronary angioplasty of anomalous coronary arteries: Case reports. Angiology. 1996;47:77-82.

27. Suryanarayana P, Lee JZ, Abidov A, Lotun K. Anomalous right coronary artery:case series \& review of literature. Cardiovasc Revasc Med. 2015;16:362-366.

28. Patel TM, Shah SC, Ranjan A, Gupta AK. Direct coronary stenting through the radial approach in an anomalous coronary artery. Indian Heart J. 2002; 54:422-424.

29. Lorin JD, Robin B, Lochow P, Lorenzo A, Sedlis SP. The right radial approach for stenting of lesions in the right coronary artery with anomalous take-off from the left sinus of valsalva. J Invasive Cardiol. 2000;12:478-480.

30. Practical Handbook of Advanced Interventional Cardiology, TIPS AND TRICKS. Nguyen T, Hu D, Chen SL, Kim MH, Saito S, Grines C et. al (eds), $4^{\text {th }}$ (Ed.), Ikari Y , Slender Transradial Intervention, Chapter 8, John Wiley \& Sons. Inc., p. 171-183. DOI:10.1002/9781118592380

31. Charey R, Spindola-France H, Grose R. Coronary angioplasty of anomalous right coronary arteries. Catheter Cardiovasc Diagn, 1993;29:233-235. 